11. Silvestrov V., Pilyutikov S. (2010) Waiting for music: lectures-conversations. Based on the materials of the meetings organized by Sergius Pilyutikov. K.: Duh i Litera. [in Russian].

12. Chigareva E. (2005) Polystylistics. The theory of modern composition. M.: Musica, 431-449. [in Russian].

13. Kholopova V. (2002) Special and non-special musical content. Moscva: Izdatelstvo MGK im. P. I. Tchaikovsky [in Russian]. sian].

14. Kholopova V. (1999) Forms of musical works. Tutorial. St.P: Lan [in RusСтаття надійшла до редакції 22.06.2016

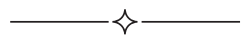

УДК 78.01(78.03, 78.05, 781.1, 781.2, 7.01, 7.06)

Таганов Олег Николаевич, кандидат искусствоведения, доцент кафедры философии и культурологии

Национального университета кораблестроения имени адмирала Макарова oltag@i.ua

\title{
МУЗЫКАЛЬНЫЙ РЕМИКС КАК ФАКТОР ФОРМИРОВАНИЯ ФИЛОСОФИИ «РИНГТОННОЙ» КУЛЬТУРЫ
}

Цель статьи - рассмотреть основные различия между ремиксом (использующим преимущественно классический музыкальный тематизм) и другими музыкальными жанрами похожей направленности, проанализировать его роль и место в формировании и функционировании современной «рингтонной» культуры. Методология: данное исследование опирается на культурологический, аксиологический, историографический и жанровый подходы. Научная новизна. Проблема современного развития музыкальных жанров в сфере легкой и популярной музыки поднимается в этой статье в конкретизированном рассмотрении жанра ремикса (главным образом классических тем и произведений). Выводы. Снижение аксиологических критериев при создании произведений в этом жанре по сравнению с подобными жанрами в прошлом обусловливает резкое падение музыкального вкуса и делает невозможной передачу и усвоение высоких художественных образцов музыки предшествующих эпох. С проблемой ускорения современной жизни и нехваткой времени для эстетичного и духовного саморазвития возникает возможность использования жанров типа ремикса как суррогата творческого поиска. Они формируют

(C) Таганов О. Н., 2016 
новые подходы и философию современного псевдокультурного человека в рамках «рингтонной» культуры.

Ключевые слова: «рингтонная» культура, ремикс, транскрипция, аранжировка.

Taganov Oleg. PhD of arts, associate professor of the faculty of philosophy and culturology, Admiral Makarov National University of Shipbuilding.

Musical remix as a factor of forming of ringtone culture philosophy.

Article purpose is considering the main differences between the remix (using mainly classical musical tematizm) and other musical genres of similar orientation, his role and the place in formation and functioning of modern «ringtone» culture are analysed. Methodology: this research relies on culturological, axiological, historiographic and genre approaches. Scientific novelty: The problem of musical genres developing in popular music sphere is considering in concrete genre of remix (mainly of classical themes and works). Conclusions. Falling down of axiological criteria in creating of works in this genre in comparison with same genres in the past determines extraordinary falling down of musical taste and makes the passing and assimilating of masterpieces musical works of the past impossible. Due to the problem of rising speeds of today life and limits of time for aesthetical and self developing reveals the possibility of using the genres like remix as a surrogate of creative search. They form the new approaches and philosophy of contemporary pseudocultural person within «ringtone» culture.

Keywords: «ringtone» culture, remix, transcription, arrangement.

Таганов Олег Миколайович, кандидат мистецтвознавства, доцент кафедри філософії та культурології Національного університету кораблебудування імені адмірала Макарова

\section{Музичний ремікс як фактор формування філософії рінгтонної куль- тури}

Мета статmі - розглянути основні відмінності між реміксом (що використовує переважно класичний музичний тематизм) і іншими музичними жсанрами схожої спрямованості, проаналізувати його роль $i$ місце у формуванні та функціонуванні сучасної "рінгтонної» культури. Методологія: дане дослідження спирається на культурологічний, аксіологічний, історіографічний та жанровий підходи. Наукова новизна. Проблема сучасного розвитку музичних жанрів у сфері легкої та популярної музики постає у цій статті у конкретизованому розгляді жанру реміксу (головним чином класичних тем і творів). Висновки. Зниження аксіологічних критеріїв при створенні творів у цьому жанрі в порівнянні з подібними жканрами у минулому обумовлює різке падіння музичного смаку $i$ унеможливлює передачу $і$ засвоєння високих художніх прикладів музики попередніх епох. 3 проблемою прискорення сучасного життя та невистачанням часу для естетичного та духовного саморозвитку виникає можливість використання жанрів типу реміксу як сурогату творчого пошу- 
ку. Вони формують нові підходи і філософію сучасної псевдокультурної людини в рамках «рингтонної» культури.

Ключові слова: «рингтонна» культура, ремікс, транскрипція, аранжування.

Актуальность исследования. Тенденции развития современного музыкального искусства представляют широкое поле для прогностических исследований, поскольку стилевое и жанровое разнообразие не выявляет доминантного «мейнстрима» в силу сложной полиструктурной динамики современной музыкальной культуры. Тем не менее существуют некоторые феномены и факторы, влияющие на развитие большого сегмента музыкальных стилей и жанров не только академической, но и джазовой, электронной музыки и других направлений. Одним из таких факторов является активное использование «эффекта узнавания» хорошо известного музыкального произведения (чаще - его наиболее характерного элемента) в сочетании с новыми ритмо-тембровыми условиями его звучания.

В современной музыкальной практике этот тип тематического преобразования называется ремикс.

Цель статьи. В этой статье мы рассмотрим основные различия между ремиксом (использующим преимущественно классический музыкальный тематизм) и другими музыкальными жанрами похожей направленности и проанализируем его роль и место в формировании и функционировании современной «рингтонной» культуры.

Изложение основного материала. В онтологическом аспекте ремикс берет свое начало в эпоху средневековья, используя канонические музыкальные формулы григорианского хорала в качестве оригиналов для хоральных обработок композиторов Возрождения и барокко. Композиторская практика как феномен (с ее авторством, многочисленными техниками, избеганием плагиата и т. д.) появляется намного позже феномена переформатирования канонического инварианта музыкальной темы. Практика заимствования музыкального материала была настолько распространенной, что создание нового произведения в то время можно рассматривать в аспекте «творческого отражения», а не «новаторского моделирования».

Развитие и влияние на процесс создания произведений искусства гуманистических идей Возрождения привели к индивидуализации творческой практики. Большее внимание в XVI-XVII веках стало уделяться личности создателя каждого произведения искусства. Усиление эгоцентрической составляющей в творческом процессе послу- 
жило возникновению понятия композитор, как «человек, пишущий музыку, которой ранее не существовало и которая начинает существовать только в результате прочтения нотной записи, составленной композитором» [5, 238].

Дальнейшее развитие привело к возникновению широкого спектра композиторских стилей. Каждый из них оригинален и узнаваем. В процессе количественного накопления и осмысления знаний о звуковой природе и музыкальной структуре, связанной с ней, возникают моменты заимствования композиторами музыкально-тематического материала друг у друга с целью дальнейшего преобразования или другого его прочтения. Возникает целый ряд жанров, позволяющих легально использовать в своем творчестве идеи других авторов. Среди таких жанров можно выделить «Вариации на тему», «Фантазии на тему», «Транскрипции». Причем транскрипции и фантазии вошли в жанровую практику гораздо позже вариаций. Узнавание ярких, запоминающихся мелодий из уже известных произведений других авторов, как правило, привлекало к новым жанрам большое внимание и обеспечивало популярность новому произведению среди слушателей.

Транскрипции ${ }^{1}$ появились в XVI-XVII в. как переложение вокальных произведений для исполнения на музыкальных инструментах. Но настоящего расцвета этот жанр достиг в эпоху позднего классицизма и романтизма. В первую очередь это касается фортепианных транскрипций Ф. Листа, Ф. Бузони, позже - Л. Годовского, М. А. Балакирева, С. В. Рахманинова, К. Таузига, а также скрипичные Т. Ф. Крейслера. Одним из ярких воплощений жанра транскрипции в XX веке стала, например, балетная сюита Р. Щедрина «Кармен». Вероятно, это самый масштабный пример транскрипции целого симфоническо-сценического произведения. Интересно, что если Ж. Бизе заимствовал и адаптировал многие танцевальные мелодии для своей оперы из бытового мелоса современной ему Испании, то Р. Щедрин реадаптировал уже вокальный вариант этих мелодий для балетного исполнения. В рамках адаптации к балетно-сценическим условиям исполнения состав симфонического оркестра был значительно расширен за счет группы ударных инструментов. В самой музыке появляются новые детали, интересные ритмические и звуко-колористические решения, на передний план выводится именно танцевальная природа этой музыки. В этом и проявляется огромная художественная ценность и самостоятельность творческого замысла. 
Необходимо различать понятия транскрипции и трактовки, поскольку трактовка не предполагает изменений в фиксированном авторском тексте, а лишь расставляет по-иному логические и художественные акценты в конкретном исполнительском контексте. Транскрипция же фиксирует переосмысление музыкальной идеи в измененном нотном (текстовом) воплощении.

Помимо художественной адаптации произведения к другому инструменту, транскрипция имеет также другое значение, а именно «переделка музыкального произведения с целью упростить его исполнение или с какой-нибудь иною целью» [6, 391]. В данном случае транскрипция рассматривается не с художественной точки зрения, а с утилитарной. Упрощение в дальнейшем становится одним из основных факторов «рингтонной» культуры, о которой речь пойдет ниже.

Еще одной разновидностью заимствования мелодии является $n a-$

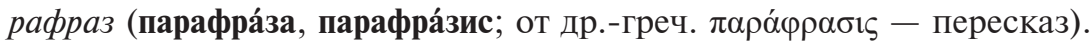
Как правило, жанр парафраза тесно связан с темами известных опер или народных мелодий. В нем используются принципы варьирования, редуцированного (облегченного, упрощенного) изложения, сокращения, стилевой трансформации и др. «Пересказ» в данном случае не преследует сохранение оригинала близко к тексту. Передача художественного смысла «своими словами» может иметь самый широкий диапазон допущений. И зачастую такая трансформация направлена на максимальную возможность ассимиляции исходного материала широкой слушательской аудиторией, то есть целью является упрощение и максимальная доступность.

Можно ли рассматривать аранжировку как одну из разновидностей заимствования?

Очевидно, нет. Поскольку в процессе аранжировки основным критерием остается аутентичность замысла и сохраняется полное авторство произведения, то сам факт заимствования отсутствует. В качестве примера приведем гениальную аранжировку М. Равелем «Картинок с выставки» М. Мусоргского. Симфоническое воплощение этого произведения обеспечило ему новые краски и проявило новые грани этой музыки. Транскрипция ли это, переложение? В некоторой степени да, но с оговоркой, что адаптация в этом случае направлена на расширение потенциальных возможностей оригинала, а не на приспособление к ограниченным возможностям исполнения.

Но вернемся к понятию ремикс, о котором мы говорили в начале. Музыкальная практика конца XX века разделилась на множество не 
только стилевых направлений, но на большое множество социальнокультурных музыкальных пластов, каждый из которых имеет свои законы развития, свои тенденции и факторы трансформации.

$\boldsymbol{P е м и к с}^{2}$ академической музыки «консервирует» наиболее популярные музыкальные идеи, преподнося их в упрощенной форме и крайне «адаптированном» виде. Это в первую очередь касается танцевальной стилистики ремиксов, которая сводит восприятие красивейших образчиков музыкального искусства к ассимиляции их через активно-мышечную деятельность или навязчиво-лапидарную ритмическую конструкцию, «впечатываемую» в сознание вместе с мелодическим остовом какого-либо академического шедевра. Таким образом, ремикс стал ярким выразителем китч-культуры в музыкальной сфере.

Большую сферу современного «звучащего пространства» охватывает так называемая легкая музыка, использующая целый арсенал инструментов и методов, позволяющих создать иллюзию сопричастности с высоким искусством у максимально широкой слушательской аудитории. Одним из таких методов как раз и стало упрощение и «деэстетизация» шедевров классической и академической музыки в условиях современного медиа-рынка. Вульгаризация высоких эстетических критериев искусства является одним из признаков культуры китча. И хотя по утверждению Т. Адорно «китч, словно гном, ускользает от любой дефиниции» $[1,345]$, на наш взгляд, можно привести одно из выражений Клемента Гринберга, характеризующего суть этого явления: «Китч - продукт промышленной революции, которая урбанизировала массы Западной Европы и Америки и создала то, что называют всеобщей грамотностью» $[4,40]$. Любопытным представляется тот факт, что музыкальный ремикс, в отличие от парафраза, транскрипции и других жанров, существующих в академической музыке и имеющих высокие художественные образцы, использует заимствованный музыкальный материал в качестве «цепляющего крючка» (hook) для удержания внимания слушателя на том суррогатном «музыкальном продукте», который ничего общего с художественностью не имеет.

Причины появления такого жанра, как ремикс, опираются в первую очередь на сведенное к абсолюту понятие наглядности (Fasslichkeit). Чтобы пояснить отрицательную роль такой абсолютизации, необходимо обратиться к теории познания. Современная система обучения стремится избегать подачи материала в виде каких-либо 
абстракций, поскольку абстрактное мышление требует определенной работы мышления, определенного напряжения в процессе выстраивания ассоциативных абстрактных связей. Другое дело - зрительный образ. Схватывается моментально, прост, иконичен, не требует особого анализа и сопоставления с чем-либо кроме себя самого. Наглядность как инструмент - очень хороший помощник на определенном этапе. Иисус Христос, проповедуя, обращался к наглядным, понятным для простого народа образам для более яркого понимания тех простых истин, которые легли в основу христианского учения. Именно этот тип «наглядности» имел в виду Антон Веберн, говоривший, что «наглядность (Fasslichkeit) является высшим законом всякого выражения мысли» $[3,23]$. В контексте рассмотренных выше жанров (вариаций, парафразов и т. д.), использующих заимствования для получения нового художественного произведения, необходимо признать обоснованность взглядов А. Веберна, указывавшего, что достичь наглядности лучше всего «...путем повторения. На этом зиждется все формообразование, все музыкальные формы строятся на этом принципе» $[3,31]$.

Однако попытка сведения сложных понятий и тонких эстетических и этических структур к тривиальному (якобы) аналогу с применением метода доступной наглядности является тупиковым путем к деградации абстрактного мышления и, как следствие, к общему социально-культурному упадку.

Рассматривая ремикс как «инструмент наглядности», мы обнаруживаем указанный А. Веберном принцип повторности в самом примитивном аспекте его использования. Вместо того чтобы служить узнаваемости художественного образа, повторение становится «вдалбливанием» статичной обескровленной интонации, становясь антихудожественным инструментом манипуляции musica corpo.

Весьма интересно хотя бы обзорно затронуть различия в подходах к принципу повторности в европоцентристской и восточноазиатской традиции. Удивительный феномен сочетания простой повторяющейся интонационной основы и постоянно меняющегося музыкального окружения мы находим в традициях мугамов и макомов ирано-персидской традиции, основанной на одноголосном изложении. Повторность базовой интонации здесь никогда не становится однообразной за счет микромелизматики, метрической неоднородности и колоссального ритмического разнообразия во всех его проявлениях. Именно они способствуют почти безграничному 
развитию в одноголосии линеарных мелодических структур. Индийская рага также может охватывать в своем исполнении не один час. Очевидно, что повторяемость интонационных формул приобретает гораздо больший художественный потенциал в условиях применения более тонкого деления музыкальной октавы на треть- и четверть-тоновые отрезки (в отличие полутоновых в европейской системе темперации). Система шрути имеет двадцать два неравных интервала. Они связаны с понятием цвета и эмоционального состояния. Повторность в этих условиях не несет в себе механистичности. Разнообразие при повторности лежит в большем «индуктивном» проникновении в суть изменяющегося звука. В этих традициях можно говорить о таком понятии, как тембро-ритм. При восприятии музыки восточных традиций мышление перестраивается на более детализированное восприятие, оттачивается филигранность слуховых оценок, расширяется сознание и обогащается база ассоциативных элементов.

Ничем подобным ремикс не располагает.

Определив, чем по сути является жанр ремикса в современной системе эстетического воспитания, мы можем выяснить его место и роль в формировании путей дальнейшего развития музыкальной культуры.

Система свертывания информации в блоки для более быстрого усваивания приводит в настоящий момент к «свертыванию культуры», поскольку эмоционально этот «сверток» наполнить ничем не возможно. Сокращенная «программа окультуривания» была рассмотрена уже упомянутым нами социологом и культурологом Теодором В. Адорно. Он определил основные векторы этого процесса, обозначив причины динамики такого развития. Одной из причин он назвал вульгарность. Это понятие связано с понятием широких народных масс (от лат. vulgus народ), как правило, не имеющих достойного образования. Особенно это касается сферы эстетического вкуса. Вероятно, именно поэтому термин вульгарность получил наибольшее применение в области культуры, эстетики, искусства и стал противопоставляться понятию красота. В применении к музыке Т. В. Адорно указывал следующее: «Вульгарность состоит в отождествлении с тем принижением, которого не может превозмочь пленное сознание, ставшее его жертвой. Если так называемое низкое искусство прошлого более или менее бессознательно осуществляло такое принижение, если оно отдавало себя в распоряжение униженных, то теперь само унижение ор- 
ганизуется, управляется, а отождествление с ним осуществляется по плану. Вот в чем позор легкой музыки, а не в том, в чем ее упрекают в бездушии или несдержанной чувственности» $[2,31]$.

То есть свертывание эстетической информации в компактный вид ведет к потере ценностной составляющей этой информации. Такая ситуация характерна для так называемой «рингтонной» культуры, стремящейся «упаковать» ценные культурные образцы в наиболее компактный и «оптимизированный» к моментальному усвоению вид. «Как результат, мы наблюдаем тенденцию к излишней концептуализации в творчестве либо полное ее отсутствие (также возведенное в концепт). Исчезает музыкальная эмоция» [7, 45]. Приоритет имеет структурная информация; процессуальностью эстетического наполнения художественным смыслом и ценностью в этом случае полностью пренебрегают. Именно такую потерю художественной ценности (при отсутствии создания новой ценности) можно наблюдать на любом примере ремикса академической музыки.

В условиях нарастания дефицита времени в современном способе жизни все временные виды искусства будут стремиться к уменьшению времени (и пространства) для своего существования. Но в условиях такой тенденции невозможна или очень затруднена одна из фундаментальных функций культуры - преемственность культурных ценностей. Разница в аксиологических подходах к проблеме времени и пространства в искусстве в современных условиях и в прошлом не позволяет адекватно «разместить» накопленный культурный багаж в прокрустово ложе современного индивидуального пространственновременного континуума. Жанр ремикса - это очень неуклюжая попытка решения такой проблемы. Но несмотря на неуклюжесть, она продолжает использоваться для решения указанного противоречия при отсутствии альтернатив и становится фактором, участвующим в формировании нового мировоззренческого подхода к музыке и искусству в целом.

Еще одним из аспектов использования ремикса как некоего творческого интеллектуального продукта является суррогатный метод псевдотворчества, которое характерно для него. Человек, не способный сделать что-то более масштабное и интересное с художественной точки зрения, пытается путем компоновки известного музыкального тематизма с тембро-ритмическими заготовками элементарнейшего уровня приблизить себя к собственному осознанию себя в статусе «творца». Самовыражение стремится к реализации в 
любом доступном виде и на любом доступном уровне эстетического развития.

Французскому романисту и литературному критику Анатолю Франсу принадлежит высказывание: «Искусству угрожали два чудовища: художник, который не является мастером, и мастер, который не является художником». Философия «рингтонной» культуры строится на принципе всяческого поощрения и создания таких «чудовищ».

Выводы. Логически из вышесказанного вытекает следующая сентенция: «жанр» ремикса не является чем-либо принадлежащим к искусству, поскольку не способен нести художественный смысл и эстетический образ. Человек, стремящийся выразить себя в этом жанре, не является Художником в широком смысле этого слова. Дальнейшее использование и попытка развития «жанра» ремикса приведет к ускорению реализации концепции «рингтонной» культуры и распространению ее философии, что в свою очередь чревато девальвацией культурных ценностей и духовному обнищанию общества.

\section{Примечания:}

${ }^{1}$ Транскрипция (лат. transcriptio, букв. - переписывание) - переложение, переработка муз. произв., имеющие самостоят. художеств. значение. Различают два вида Т.: приспособление произв. для др. инструмента (напр., фп. Т. вокального, скрипичного, оркестрового соч. или вокальная, скрипичная, оркестровая Т. фп. соч.); изменение (в целях большего удобства или большей виртуозности) изложения без перемены инструмента (голоса), для к-рого предназначено произв. в оригинале». (Музыкальная энциклопедия. - М.: Советская энциклопедия: Советский композитор. Под ред. Ю. В. Келдыша. 1973-1982.)

${ }^{2}$ Remix англ. - версия музыкального произведения, записанная позже оригинальной версии, как правило, в более современном варианте аранжировки. Иногда создается путём «перемешивания» нескольких частей исходной композиции, наложения на неё различных звуков, спецэффектов, изменения темпа, тональности и т. п. В наиболее общепринятом смысле ремиксом называют любой новый вариант композиции или произведения. - wikipedia

\section{СПИСОК ЛИТЕРАТУРЫ}

1. Адорно Т. Эстетическая теория / Пер. с нем. А. В. Дранова. М.: Республика, 2001. (Философия искусства). 527 с.

2. Адорно Т. Избранное: Социология музыки. М.; СПб.: Университетская книга, 1998. 445 с. 
3. Веберн А. Лекции о музыке. Избранные письма / Пер. с нем. В. Г. Шнитке. М.: Музыка, 1975. 143 с.

4. Гринберг К. Авангард и китч / пер. с англ. А. Калининой/ Художественный журнал, вып. 60, 2005 / Partisan review,VI, no.5, pp 34-49 URL: http:// xz.gif.ru/numbers/60/avangard-i-kitch

5. Мартынов В. Конец времени композиторов / Послесл. Т. Чередниченко. М.: Русский путь, 2002. 296 с.

6. Полный словарь иностранных слов, вошедших в употребление в русском языке / сост. Попов М., 1907. 458 с.

7. Таганов О. Рингтонна культура та сучасний музичний генезис // Музичне мистецтво і культура. Науковий вісник Одеської національної музичної академії ім. А. В. Нежданової. Вип. 17. Одеса, «Астропринт», 2013. С. 42-52

\section{REFERENCES}

1. Adorno, T. (2001). The aesthetic theory. M. : Respublika [in Russian].

2. Adorno, T. (1998). Favourites: Music sociology. M.; SPb.: University book [in Russian].

3. Webern, A. (1975). Lectures about music. The chosen letters. M.: Music [in Russian].

4. Greenberg, C. (2005). Vanguard and kitsch. The Art magazine (issue 60) Partisan review, VI, (No. 5), (pp 34-49). Retrieved from: http://xz.gif.ru/numbers/60/ avangard-i-kitch [in Russian].

5. Martynov, V. (2002). End of time composers. M.: Russian way [in Russian].

6 . The unabridged dictionary of the foreign words which have entered the use in Russian (1907). Edit. M. Popov M. priests [in Russian].

7. Taganov, O. (2013). Ringtone culture that modern music genesis. Music art and culture scientific bulletin of the Odessa National A. V. Nezhdanova Academy of Music (Vol. 17), (pp 42-52) [in Ukrainian].

Стаття надійшла до редакції 08.06.2016

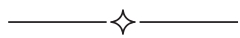

